
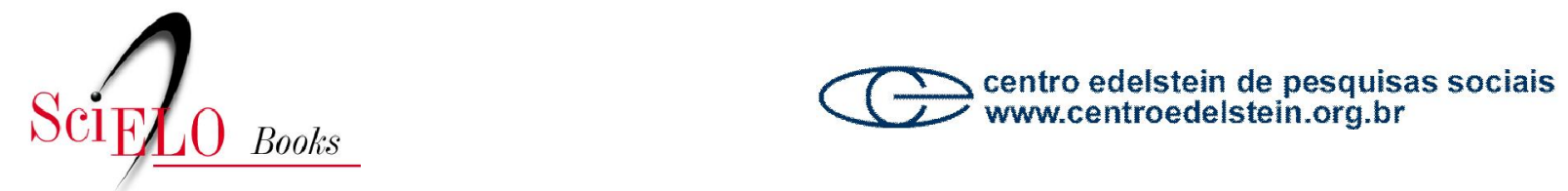

\title{
III. A Amazônia de hoje
}

\author{
Fernando Henrique Cardoso \\ Geraldo Müller
}

SciELO Books / SciELO Livros / SciELO Libros

CARDOSO, FH., and MÜLlER, G. Amazônia: expansão do capitalismo [online]. Rio de Janeiro: Centro Edelstein de Pesquisas Sociais, 2008. pp. 40-54. A Amazônia de hoje. ISBN: 978-85-9966273-1. Available from SciELO Books $<\underline{\text { http://books. scielo.org }>\text {. }}$

\section{(1) (1) $\Theta(9)$}

All the contents of this chapter, except where otherwise noted, is licensed under a Creative Commons Attribution-Non Commercial-ShareAlike 3.0 Unported.

Todo o conteúdo deste capítulo, exceto quando houver ressalva, é publicado sob a licença Creative Commons Atribuição Uso Não Comercial - Partilha nos Mesmos Termos 3.0 Não adaptada.

Todo el contenido de este capítulo, excepto donde se indique lo contrario, está bajo licencia de la licencia Creative Commons Reconocimento-NoComercial-CompartirIgual 3.0 Unported. 


\section{A Amazônia de hoje}

Nos capítulos anteriores esboçou-se o quadro histórico do processo de povoamento da Região norte junto com um apanhado dos desenvolvimentos econômicos dos últimos trinta anos. Cabe, agora, aprofundar a análise da Amazônia atual, sempre pelo prisma econômicopolítico do fenômeno demográfico.

Os mais de três milhões e meio de $\mathrm{km}^{2}$ contavam, em 1940, com uma população de $1400 \mathrm{mil}$; dez anos depois, aumentava em. 450 mil; entre 1950 e 60, passa de pouco mais de 1,8 milhões para 2,6 milhões; em 1970, a população ultrapassa a casa dos 3,6 milhões, constituindo-se a Amazônia em área de imigração.

Essa evolução quantitativa será a seguir detalhada para que se analisem os movimentos populacionais em sua relação com a divisão social do trabalho pelo ângulo do rural e do urbano. Nos capítulos seguintes, será apreciada mais minuciosamente como elemento da dinâmica do setor rural e do setor urbano.

\section{O rural e o urbano. Divisão do trabalho}

O processo de urbanização da região amazônica nos últimos 20 anos foi acentuado, como ocorreu em todo o país. Concentrou-se, porém, em praticamente todas as unidades da região, quase só nas Capitais. Em 1950, apenas cerca de 500 mil pessoas habitavam núcleos urbanos com dois mil e mais habitantes. Dez anos depois, esse número gira em torno de 900 mil. Em 1970, chega a um milhão e meio. Observe-se que a distinção entre o urbano e o rural assenta-se nos critérios censitários, i.e., administrativos.

Assim, entre 1950 e 1970, a taxa de urbanização da região elevou-se de 26 a $41 \%$. Excluindo-se, no entanto, as Capitais, a população dos núcleos urbanos representava apenas 13,5\% da população total em 1970. Em quase todas as unidades da Federação da região o quadro é semelhante: a taxa eleva-se de 10 a $30 \%$ em 1950 a cerca de 40 a $50 \%$ em 1970; excetuando-se as Capitais, as taxas não atingem $10 \%$ a não ser para a última data. A principal exceção é o Estado do Pará, onde a proporção de população urbana (sem Belém) é de 15\%, seguido por Rondônia, com quase 
$14 \%$, refletindo as crescentes levas de ocupação e formação de pequenos núcleos urbanos. O Pará é a única unidade da região onde se encontram núcleos urbanos de mais de 10 mil habitantes (em número de 8) em outras microrregiões que não a da Capital.

\section{II - Taxa de urbanização,* Unidades da Federação, Região norte} 1950-1960-1970

\begin{tabular}{|l|c|c|c|}
\hline Unidades da Federação & $\mathbf{1 9 5 0}$ & $\mathbf{1 9 6 0}$ & $\mathbf{1 9 7 0}$ \\
\hline \multirow{2}{*}{ Rondônia } & 30,4 & 37,5 & 50,3 \\
& $(7,0)^{* *}$ & $(10,1)$ & $(13,5)$ \\
\hline \multirow{2}{*}{ Acre } & 11,4 & 16,5 & 25,4 \\
& $(3,2)$ & $(5,7)$ & $(9,4)$ \\
\hline \multirow{2}{*}{ Amazonas } & 21,1 & 28,9 & 39,3 \\
& $(3,7)$ & $(7,6)$ & $(9,6)$ \\
\hline \multirow{2}{*}{ Roraima } & 28,3 & 34,5 & 40,3 \\
\multirow{2}{*}{ Pará } & $(0)$ & $(0)$ & $(0)$ \\
\hline \multirow{2}{*}{ Amapá } & 27,0 & 35,7 & 42,7 \\
& $(6,9)$ & $(11,8)$ & $(15,2)$ \\
\hline \multirow{2}{*}{ Região norte } & 26,0 & 40,0 & 45,0 \\
& $(0)$ & $(0)$ & $(0)$ \\
\hline
\end{tabular}

Fonte: Censos de 1950, 1960 e 1970.

* Proporção da população residente em núcleos de 2 mil habitantes ou mais.

** Taxa de urbanização computada excluindo-se a população das Capitais.

Tal fato reflete a maior densidade da população rural neste Estado, ao mesmo tempo que revela estar em constituição aí, principalmente na parte leste do Estado (Marabá, Jatobal, Tucuruí, Itinga, Paragominas, entre outras cidades), uma rede de núcleos de mais de 2 mil habitantes que estão a denotar o avanço da frente pioneira agropecuária provinda do nordeste e do sul (Goiás e Maranhão).

O crescimento urbano tendeu a ser maior nas Capitais menores da região (em geral em ritmos bem superiores a $10 \%$ a.a.); Belém cresceu 60 a 59\% entre 1950-60 e 1960-70, enquanto que Manaus, 72 a 86\%; este ritmo excepcionalmente alto de crescimento de Manaus na última década deve estar ligado à sua situação de Zona Franca (1967), à instalação de algumas empresas, como, por exemplo, a partir de 1958, de uma refinaria da Petrobrás.
O crescimento relativo urbano/rural apresentou fortes diferenciais, mostrando a continuação dos fluxos do campo para a cidade. Os crescimentos por decênio constam na Tabela III.

III - Crescimento percentual da população total, rural e urbana, região norte 1950-60 e 1960-70

\begin{tabular}{|l|c|c|}
\hline & $\mathbf{1 9 5 0 - 6 0}$ & $\mathbf{1 9 6 0 - 7 0}$ \\
\hline População Total & $41 \%$ & $39 \%$ \\
\hline População Rural e Semi-urbana & $28 \%$ & $22 \%$ \\
\hline População Urbana & $77 \%$ & $74 \%$ \\
\hline
\end{tabular}

Fonte: Censos de 1950, 1960 e 1970

Examinando-se o crescimento demográfico por unidade da Federação, nota-se que ele foi maior, tanto para a população total como para a urbana nos territórios que são áreas de ocupação mais recente: a população total mais que triplicou no Amapá e Rondônia, o que se deve, certamente, à exploração do manganês, do estanho, do ouro e ao processo de colonização. O crescimento da população de Roraima vincula-se ao desenvolvimento da exploração das madeiras e peles, da pecuária e de alguns pontos de colonização ${ }^{65}$. Nos Estados o crescimento já foi bem menor

Diferenciais semelhantes observam-se para o crescimento da população rural nas várias partes da região, nos dois últimos decênios.

Um exame um pouco mais preciso do crescimento das populações rurais e urbanas pode ser feito com base na tabela do Censo Demográfico que indica o crescimento das populações rurais e urbanas por microrregião e por unidade da Federação, entre 1950 e 1970.

De importante observa-se que o crescimento da população rural já não se mostra muito elevado nos anos 50, o que indica certa emigração para as cidades da região ou mesmo para fora da região; o crescimento diminui ainda mais nos anos 60, já que o êxodo rural se intensifica. Algumas microrregiões apresentam, nos anos 50, crescimento mais elevado, ao redor

\footnotetext{
65 "Com a instalação de serrarias para atender às empreiteiras, a demanda de energia elétrica dobrou nos últimos dois anos. O Governo do Território passou a se preocupar com a instalação de uma hidroelétrica". Vitela, 07/10/1974, p. 36.
} 
ou superiores a 50\% ${ }^{66}$ É o caso dos Territórios de Rondônia, Roraima e da Microrregião 27 do Amapá, onde a ocupação econômica é recente (extração do manganês, projeto agrícola "Grão") ${ }^{67}$, o que provocou, inclusive, um aumento da população rural.

Crescimentos semelhantes ocorrem também no Estado do Amazonas, principalmente na Microrregião 10, do médio Amazonas, e 8, vinculados à juta. As Microrregiões 12 e $13^{68}$, em boa parte continuação paraense da Microrregião 10 do Estado do Amazonas, tiveram um crescimento de 36\%; elas compreendem um terço da área do Pará. Se dispuséssemos de dados para áreas menores poderíamos precisar melhor tais modificações demográficas e sua vinculação com a juta, de um lado, e o gado com a extração da castanha, de outro.

Em todos os casos, exceto o do Amapá e o da área das Microrregiões 19 e 20 do Pará, frente de expansão agrícola-extrativa-pecuária, o crescimento no decênio 1969-70 foi bem menor.

O crescimento urbano, retratado na tabela sobre crescimento percentual da população, repete o que já observamos: ele é acentuado durante ambos os decênios. Frequentemente é maior o dos núcleos menores que o das Capitais. Mesmo crescimentos elevados de pequenos núcleos representam taxas de urbanização - e níveis de divisão social de trabalho pouco elevadas, conclusão a que não se pode fugir quando se deixam de lado as concentrações populacionais das Capitais.

A distribuição da população entre urbano e rural expressa a divisão social do trabalho segundo a massa de mão de obra requerida pela dinâmica da organização econômica e política da região. No fim do ciclo da borracha (1920), contando como urbanos os núcleos de Manaus e Belém, 28\% da população amazônica residiam nos municípios destas cidades e mais de 1

\footnotetext{
${ }^{66}$ Veja-se BASA, "Movimentos Migratórios, Nomadismo e Êxodo," pp. 69 a 74, onde são descritos os movimentos do caboclo amazonense, a desruralização da população, a migração nordestina e japonesa.

${ }^{67}$ Visão, 07/10/1974, p. 36. Neste trabalho, veja-se nota 85.

${ }^{68}$ Os dados dos municípios de 1950 e 1960 foram agrupados segundo a divisão por microrregiões de 1970. Em alguns casos, para se obterem unidades de áreas comparáveis nas três datas, foi preciso juntar duas microrregiões. Nos casos das Microrregiões 12 e 13, 14 e 15, 22 e 26, 38 e 39 a comparabilidade de áreas exigiu alterações na sua composição municipal, que passou a diferir um pouco da definição pelo Conselho Nacional de Geografia.
}

milhão no meio rural. Essa divisão refletia as exigências sociais de obtenção e beneficiamento do látex nos seringais e de comercialização e financiamento nas cidades.

Com a penetração das frentes pioneiras, notadamente a partir das décadas de 1950 e 60, começaram a surgir numerosos pequenos núcleos que repetiam sua organização de base agropecuária ou mineradora à medida que, contando com disponibilidade de terras e veios mineradores, aumentava o número de seus habitantes. Estes núcleos criaram, sem dúvida, uma diferenciação na divisão do trabalho, mas embrionária, já que, na realidade, cada núcleo repetia a organização do outro, que consistia no trabalho familiar voltado para o autoabastecimento e para pequenas feiras locais.

Durante essas mesmas décadas, expandem-se, extensivamente, os setores da juta e da castanha que, igualmente, criam pequenos núcleos urbanos. Note-se, no entanto, que essa diversificação produtiva - exceção feita às áreas mais puramente agrícolas - atendia a demandas externas à região, que eram canalizadas via centros urbanos, reproduzindo o papel de intermediação desses centros reiterando, assim, a divisão entre o urbano e o rural. O domínio do transporte fluvial era um dos componentes estratégicos dessa reiteração, processo que, em grande parte, ainda persiste atualmente. Mas, à medida que frentes se afastam das vias fluviais navegáveis e se apossam da terra firme, surgem as estradas, vicinais, municipais etc., até atingir o eixo da Belém-Brasília, que as conecta com mercados regionais do centro e do sul. A comercialização de excedentes agrícolas, mas, principalmente, extrativos, como a madeira, através dessas vias terrestres, incrementa a taxa de urbanização daqueles pequenos núcleos de até 2 mil habitantes. Estes, excluindo-se as Capitais (Tabela II), apresentavam em 1950 uma taxa de urbanização superior à 8\% e, 20 anos depois, 13,5\%.

As expansões econômicas assinaladas que criaram novos setores de atividade no meio rural provocaram não só o crescimento de pequenas aglomerações humanas mas também o de núcleos maiores. Prova disso é a relativa desconcentração urbana ocorrida entre 1920 e 1970: na primeira data, $28 \%$ da população residiam nas duas grandes Capitais; 50 anos depois, a proporção cai para $20 \%$.

A redistribuição da população no meio rural e no meio urbano poderá ser apreciada de um modo um pouco mais preciso se tomarmos as 
informações estatísticas disponíveis sobre a população economicamente ativa (PEA).

\section{Caracterização geral do emprego}

Que a diferenciação setorial do emprego na Região norte, comparativamente a outras regiões brasileiras do centro-sul, é incipiente, nota-se facilmente pelo escrutínio das informações estatísticas censuais relativas à distribuição do emprego.

Para toda a região, em 1960, 2/3 da PEA estavam no primário, 6\% nas atividades industriais e $28 \%$ nas outras atividades. Entretanto, deixando de lado as microrregiões onde se situam as capitais, apenas uma (a 19, no Pará) ${ }^{69}$ apresenta proporção de emprego, nas atividades agropecuárias, ligeiramente inferior a $2 / 3$. A grande maioria das outras microrregiões exibia porcentagens superiores a $80 \%$, ou mesmo $90 \%$, neste setor.

Em 1970 a situação havia mudado um pouco. Deixando de lado as microrregiões das Capitais, tão-somente parte das microrregiões do Pará possuíam menos de 3/4 do emprego nas atividades agropecuárias (situandose no geral esta proporção entre 60 e $70 \%$ ); este é o caso principalmente das microrregiões mais próximas de Belém (as de números 18, 19, 23 e 24), onde a estrutura setorial de emprego, entre o campo e a cidade, ganha um pouco mais de complexidade.

A Tabela IV, onde os dados são apresentados de forma mais simplificada que a constante nos Censos (separando-se para as duas datas as microrregiões das Capitais das demais), permite-nos apreciar melhor o sentido da evolução da divisão social do trabalho indicado pela distribuição setorial do emprego.

Nas microrregiões das Capitais (entre as quais o peso preponderante é de Manaus e Belém), grande proporção do emprego se situa, já em 1960, nos setores não agrícolas (61\% para o conjunto das Capitais, conforme se pode ver na tabela; excetuando-se as duas Capitais mais importantes, quer dizer, só pata as Capitais menores, tal proporção alcança pouco mais de 1/3).

\footnotetext{
${ }^{69}$ Trata-se de área polarizada por Marabá, onde se desenvolvem atualmente a pecuária e os castanhais.
}

IV - Distribuição setorial do emprego, capitais e interior,* região norte 1960 e 1970

\begin{tabular}{|c|c|c|c|c|c|}
\hline Data & $\begin{array}{c}\text { Microrregiões } \\
\text { Capitais e Interior }\end{array}$ & Total & $\begin{array}{l}\text { Atividades } \\
\text { Agro- } \\
\text { pecuárias }\end{array}$ & $\begin{array}{l}\text { Atividades } \\
\text { Industriais }\end{array}$ & $\begin{array}{c}\text { Outras } \\
\text { Atividades }\end{array}$ \\
\hline \multirow{3}{*}{1960} & $\begin{array}{c}\text { Capitais } \mathrm{n}^{\circ} . \\
\%\end{array}$ & $\begin{array}{c}293.778 \\
100,0\end{array}$ & 39,0 & 11,4 & 49,6 \\
\hline & $\begin{array}{c}\text { Interior } \mathrm{n}^{\circ} . \\
\%\end{array}$ & $\begin{array}{c}491.980 \\
100,0\end{array}$ & 82,0 & 3,0 & 15,0 \\
\hline & $\begin{array}{c}\text { Região norte } \mathrm{n}^{\circ} . \\
\%\end{array}$ & $\begin{array}{c}785.758 \\
100,0 \\
\end{array}$ & 65,9 & 6,1 & 28,0 \\
\hline \multirow{3}{*}{1970} & $\begin{array}{c}\text { Capitais } \mathrm{n}^{\circ} . \\
\%\end{array}$ & $\begin{array}{c}439.644 \\
100,0\end{array}$ & 29,7 & 17,9 & 52,4 \\
\hline & $\begin{array}{c}\text { Interior } \mathrm{n}^{\circ} . \\
\%\end{array}$ & $\begin{array}{c}589.646 \\
100,0\end{array}$ & 77,2 & 6,6 & 16,2 \\
\hline & $\begin{array}{c}\text { Região norte } \mathrm{n}^{\circ} . \\
\%\end{array}$ & $\begin{array}{c}1.029 .290 \\
100,0\end{array}$ & 56,9 & 11,4 & 31,7 \\
\hline
\end{tabular}

Fonte: Censos Demográficos, 1960 e 1970.

* Capitais: Microrregiões onde se situam as Capitais; Interior: Demais microrregiões, exceto as das Capitais.

A evolução no decênio é rápida: para o conjunto das microrregiões das Capitais o emprego não agrícola sobe para cerca de $70 \%$ e para as das Capitais menores, 50\%. O sentido maior do crescimento setorial do emprego não agrícola reside nas atividades industriais. Estas ganham mais de seis pontos porcentuais (de 11 a 18\%), enquanto os "serviços" que já continham metade do emprego total em 1960 aumentam um pouco menos de $3 \%$. Esta tendência para o crescimento relativo mais acentuado das atividades industriais verifica-se tanto nas duas principais cidades da Região norte como nas Capitais menores. O motor dessa tendência reside na instalação de moderníssimas unidades produtivas (refinarias, extrativas minerais, fiação e tecelagem, pescado, transportes marítimos e fluviais etc.) que produziram um setor novo na Região norte, realizando aí um importante salto tecnológico, passando de atividades artesanais ou unidades familiares de produção para enormes empresas capitalistas, alterando significativamente a taxa de emprego nas atividades industriais, com repercussões, se bem que mais reduzidas, no setor terciário. Caberia refletir sobre esse fenômeno a partir da constatação de que tais empresas criaram, e continuam a criar, sub-ramos industriais que não deslocam o artesanato existente, não entram em conflito com a mão de obra empregada nos ramos 
do setor primário e não possuem na Amazônia seu mercado consumidor. Não seria uma impropriedade pensar que o pessoal técnico e burocrático dessas empresas provém de fora da região, enquanto o pessoal da linha de produção é recrutado entre migrantes intrarregionais e inter-regionais, bem como de cada núcleo urbano (Manaus, Belém, Macapá etc.). (Vide "Movimentos Migratórios").

Tentaremos caracterizar a PEA do setor urbano em item específico sobre o assunto; por ora basta notar que o setor de serviços desempenhou, historicamente, um papel proeminente em termos de pessoal ocupado, graças ao tipo de economia prevalecente. Hoje (1970) a participação da PEA dos setores secundário e terciário localizados no meio rural na PEA total desses setores atinge cerca de $17 \%$, bem inferior, por exemplo, ao Maranhão, 30\%. Assim, se há uma participação artesanal na região (unidades beneficiadoras organizadas e operadas familiarmente), ela é bem menor que a do vizinho Maranhão, refletindo uma economia extrativa mercantil que, historicamente, ao instaurar-se sob a égide de produção para mercados fora da região, criou profundos liames com a economia urbana via sistema de aviamento - que fornecia boa parte dos componentes da cesta de consumo do pessoal do setor primário.

Assim, temos na região, em sua maior parte, uma divisão setorial de emprego ainda rudimentar e que no último decênio pouco se modificou. Umas poucas cidades - novamente sobressaem Belém e Manaus concentram os serviços para toda a região, desenvolvendo-se nelas, no último decênio, mais as atividades industriais. Parte delas - protegidas pelas distâncias - certamente desenvolveu pequenas oficinas e artesanato.

A evolução da população e do emprego enquanto redistribuição da massa de mão de obra requerida pela dinâmica regional, em um contexto de integração crescente à dinâmica do mercado nacional, se processa através de movimentos migratórios. Interessa determinar mais acuradamente a relação entre população/mão de obra/dinâmica regional que se realiza mediante os fluxos migratórios, com ênfase em suas magnitudes.

\section{Movimentos migratórios}

Quanto às características e à distribuição dos imigrantes, o Censo Demográfico de 1970 fornece-nos informações sobre a parte da população residente que não nasceu no município. Chamaremos tal componente de imigrantes. Trata-se de saldo, na região, dos movimentos migratórios no momento do Censo, isto é, saldo de um período longo que não podemos precisar. Nesse sentido, a mortalidade na área bem como os movimentos de retorno de migrantes refletem-se nesse saldo, diminuindo-o. As proporções do componente da população não natural dos municípios da região vão refletir tais fatores (mortalidade e migração). As proporções das correntes de população vindas de fora da região, ademais destes fatores, refletirão para o caso de uma área cujo povoamento se processou nesses últimos cem anos - os níveis de natalidade nela prevalecentes, bem como a maior ou menor recência do povoamento.

Para toda a região, em 1970, 674.083 pessoas tinham nascido fora do município onde residiam, isto é, 18,7\% do total da população da Amazônia. Esses imigrantes distribuíam-se do seguinte modo:

- pouco mais da metade $(52,5 \%)$ fazia parte de movimentos intraestaduais, ou seja, deslocamentos intermunicipais dentro do Estado de origem;

- 114.288 imigrantes, $17 \%$ do total, movimentaram-se de um Estado ou território para outro, dentro da Região norte;

— 30,5\% são oriundos de outras regiões brasileiras; há um resíduo de pouco mais de 12 mil imigrantes $(1,8 \%)$ que não puderam ser classificados; podem-se supor como provenientes de fora da Região norte.

Essas informações discriminadas segundo a unidade da Federação constam da Tabela V.

Os níveis das proporções de migrantes não variam muito (16 a 19\%), exceto em dois dos territórios de povoamento mais recente: Roraima (28\%) e Amapá (33\%). Comparando--se os territórios, os anteriores mais o de Rondônia, nota-se um padrão de migração distinto do dos Estados, principalmente dos dois mais extensos. A maior parte dos migrantes nos territórios - repita-se, de povoamento mais recente - é de proveniência (último movimento migratório) intra-regional: $12 \%$ da população de Rondônia, $26 \%$ e $30 \%$, respectivamente, da de Roraima e do Amapá.

Na maior parte da região, onde o principal povoamento é mais antigo, datando da época do ciclo da borracha (Pará, Amazonas), o principal 
contingente de migrantes na população é de proveniência intraestadual. Esta tendência é "natural" porque são áreas que ofereceram atividades alternativas nos períodos posteriores ao "ciclo da borracha" e à "batalha da borracha".

\section{V - Distribuição dos migrantes segundo o tipo do último movimento} migratório e proporções de migrantes na população, Unidades da Federação, região norte -1970

\begin{tabular}{|l|c|c|c|c|}
\hline $\begin{array}{l}\text { Unidade da } \\
\text { Federação }\end{array}$ & Intra-Estadual & Intra-Regional & Inter-Regional & Total \\
\hline Rondônia & 2.153 & 13,414 & 4.827 & 20.709 \\
pr.** & 1,9 & 12,1 & 4,3 & 18,6 \\
\hline Acre & 8.144 & 8.166 & 18.688 & 35.705 \\
pr. & 3,8 & 3,8 & 8,7 & 16,6 \\
\hline Amazonas & 109.739 & 29.393 & 36.805 & 178.789 \\
pr. & 11,5 & 3,1 & 3,8 & 18,7 \\
\hline Roraima & - & 10.586 & 869 & 11.613 \\
pr. & 0,0 & 25,9 & 2,1 & 28,4 \\
\hline Pará & 232.940 & 18.902 & 130.300 & 390.073 \\
pr. & 10,7 & 0,9 & 6,0 & 18,0 \\
\hline Amapá & 785 & 33,827 & 2.291 & 37.194 \\
pr. & 0,7 & 29,6 & 2,0 & 32,5 \\
\hline Região norte & 353.761 & 114.288 & 193.780 & 674.083 \\
pr. & 9,8 & 3,2 & 5,4 & 18,7 \\
\hline
\end{tabular}

Fonte: Tabulação especial do Censo Demográfico, 1970.

* Inclui os migrantes que não puderam ser classificados segundo o tipo de movimento migratório. ** Proporção.

O Acre constitui um caso à parte. De fato, é a unidade federativa da região que, embora a mais distante, apresenta o maior contingente da população de origem de fora da região, cerca de $9 \%$. Tal fato explica-se, como já foi dito, pela manutenção dos níveis de produção da borracha, concentrada no Acre, durante todo o período após 1945. Demograficamente, se entre 1940-1950 há um saldo positivo para esse Estado, nas duas décadas seguintes as estatísticas de Graham e Buarque acusam uma emigração praticamente em idêntico volume à imigração de 1940-1950. Como se está trabalhando com informação à base do lugar de nascimento, tudo leva a crer ter ocorrido um afluxo para o Acre seguido de um refluxo para as regiões de origem, cujo resultado, num momento determinado (1970), é favorável ao Estado; cabe mencionar, por outra parte, que os seringueiros com roçado são mais frequentes nessa área ${ }^{70}$. Os dados demográficos disponíveis não permitem responder claramente à questão, mas as informações relativas à expansão da área cultivada e da área dedicada à pecuária entre 1965 e 1972 mostram-se consistentes com o saldo populacional favorável (ver Capítulo IV).

De qualquer modo, os dados censuais indicam, para os territórios, padrões bem distintos de imigração segundo a sua localização rural ou urbana. Em geral, as proporções de migrantes são maiores nas zonas urbanas, situando-se ao redor de 22 a $24 \%$ da população, comparadas com as proporções de migrantes de 14 a $17 \%$ nas zonas rurais. As áreas novas, de povoamento mais recente, entretanto - nomeadamente o Amapá e Roraima discrepam deste padrão. Na primeira, os principais contingentes migratórios vieram para zonas urbanas, chegando a constituir quase metade da população. A instalação nestas áreas de mineração do manganês resultou, em verdade, na constituição de novas cidades, como na serra do Navio, e na alteração demográfica da Capital. Na área de Roraima, de economia agropecuária, a proporção maior de imigrantes reside na zona rural, onde constituem praticamente metade da população.

Nas direções dos fluxos, em termos de origem rural ou urbana, preponderam os movimentos rurais-rurais e urbano-urbanos. São bastante significativos também os movimentos rurais-urbanos (êxodo rural). Para a Amazônia, estes tipos de movimento distribuem-se da seguinte maneira:

\begin{tabular}{|l|c|c|}
\hline Tipo & Imigrantes & \% \\
\hline Rural-Rural & 220.692 & 32,7 \\
\hline Urbano-Rural & 79.863 & 11,8 \\
\hline Rural-Urbano & 121.750 & 18,1 \\
\hline Urbano-Urbano & 251.777 & 37,4 \\
\hline Total & 674.082 & 100,0 \\
\hline
\end{tabular}

\footnotetext{
${ }^{70}$ Observe-se ainda o seguinte: a porcentagem da área das lavouras nos estabelecimentos, no Acre, caiu de 6\% em 1950 para 4,2\% em 1960; a taxa de expansão dessa área entre 1947 e 1963 foi de 3,5\%, bem abaixo da média (Região norte. 6,4\%), permitindo pensar em uma produção de roçados. Tais dados (BASA. Cap. 7) estão a indicar a possibilidade de movimentos de vinda e ida ao "Estado dos seringais", o que ajuda a situar os dados demográficos, já que as informações disponíveis indicam que a exploração do látex acha-se intimamente vinculada às oscilações dos preços e, no caso do Acre, o afluxo de gente parece ser uma resposta a esses aumentos. No entanto, os preços da borracha constituem-se, nesse momento (1970), em apenas parte da resposta; a outra parte relaciona-se â expansão da frente agropecuária.
} 
De modo geral, ao âmbito das unidades da Federação da Região norte, nas zonas rurais, a maior parte dos migrantes provém dessas mesmas zonas (quase 3/4 para a região) e, nas zonas urbanas, provém igualmente de zonas urbanas (cerca de 2/3). Há desvios significativos desses padrões para o caso dos Territórios de Roraima e Amapá, onde grandes proporções dos migrantes residentes em zona rural provieram de zona urbana (2/3 no caso do Amapá); ademais, ainda nesse território, a proporção de migrantes rurais é maior entre os migrantes residentes nas cidades do que nos que estão no campo.

Observe-se, ainda, que para os migrantes residentes em zonas urbanas, as proporções dos provenientes do campo são maiores nas correntes que vieram de fora da região do que nas intrarregionais ou interestaduais.

A Tabela VI permite analisar a procedência dos imigrantes de cada Estado e território da região, bem como dos imigrantes de fora dela.

Os fluxos não são uniformes. Vejamos como se compõem e quais suas direções. O caso dos territórios é mais claro: do Amazonas para Rondônia e Roraima, e do Pará para o Amapá; nesses dois últimos casos, tais fluxos constituem mais de $90 \%$ dos imigrantes. Para os três Estados que foram ocupados na época do ciclo da borracha e com sua crise, pela reativação da extração da castanha e outras atividades, a maioria das migrações de fora do Estado veio de fora da região, com altas proporções do nordeste: vieram da região nordestina 63,36 e 55\%, respectivamente, dos migrantes de fora do Estado para o Acre, Amazonas e Pará.

É bom recordar que se trata sempre do último movimento migratório, aquilatado pela pergunta, no Censo de 1970, para os que não nasceram no município, em que unidade da Federação tinham o seu domicílio anterior. Assim, para a região como um todo, o Censo informa que $73 \%$ das migrações inter-regionais, comparados com $61 \%$ das migrações intrarregionais (não há destaque na informação para a parte destas provenientes de fora do Estado), efetuaram-se nos últimos 10 anos. Somente 27 e $39 \%$ desses dois tipos de movimentos migratórios ocorreram respectivamente em períodos anteriores. Estas porcentagens devem variar de Estado para Estado, o que não podemos dimensionar por falta de informaçãa ${ }^{71}$.

\footnotetext{
71 Ver MATA, Milton da, et al., Migrações Internas no Brasil. Aspectos Econômicos e Demográficos, IPEA/INPES, Rio de Janeiro, 1973, pp. 56 e 63.
}

VI a - Estado de proveniência dos migrantes de fora do

Estado Unidades da Federação, Região norte, 1970

\begin{tabular}{|c|c|c|c|c|c|c|c|}
\hline & \multicolumn{6}{|c|}{ Região } \\
\hline & & $R O$ & $A C$ & $A M$ & $R R$ & $P A$ & $\boldsymbol{A P}$ \\
\hline \multirow{2}{*}{ Rondônia } & $n^{o}$. & - & 2086 & 9096 & 78 & 2154 & - \\
\hline & $\%$ & - & 11,2 & 49,0 & 0,4 & 11,6 & - \\
\hline \multirow{2}{*}{ Acre } & $n^{o}$. & 57 & - & 6804 & 50 & 1255 & - \\
\hline & $\%$ & 0,2 & - & 24,7 & 0,2 & 4,6 & - \\
\hline \multirow{2}{*}{ Amazonas } & $n^{o}$. & 1921 & 13060 & - & 1282 & 12970 & 160 \\
\hline & $\%$ & 2,8 & 18,9 & - & 1,9 & 18,8 & 0,2 \\
\hline \multirow{2}{*}{ Manaus } & $n^{o}$. & 1760 & 9006 & - & 1282 & 12734 & 160 \\
\hline & $\%$ & 2,9 & 14,8 & - & 2,1 & 21,0 & 0,3 \\
\hline \multirow{2}{*}{ Roraima } & $n^{o}$. & - & - & 10507 & - & 79 & - \\
\hline & $\%$ & - & - & 90,5 & - & 0,7 & - \\
\hline \multirow{2}{*}{ Pará } & $n^{o}$. & 360 & 2100 & 12275 & 60 & - & 4107 \\
\hline & $\%$ & 0,2 & 1,3 & 7,8 & 0,0 & - & 2,6 \\
\hline \multirow{2}{*}{ Belém } & $n^{o}$. & 360 & 1008 & 8342 & - & - & 3456 \\
\hline & $\%$ & 0,6 & 1,8 & 14,7 & 0,0 & - & 6,1 \\
\hline \multirow{2}{*}{ Amapá } & $n^{o}$. & - & 274 & 424 & - & 33130 & - \\
\hline & $\%$ & - & 0,8 & 1,2 & - & 91,0 & - \\
\hline \multirow{2}{*}{ Região } & $n^{o}$. & 2338 & 17520 & 39106 & 1470 & 49588 & 4267 \\
\hline & $\%$ & 0,7 & 5,5 & 12,2 & 0,5 & 15,5 & 1,3 \\
\hline
\end{tabular}

Para o Acre, segundo consta na Tabela VI, quase $1 / 5$ veio do Amazonas e mais da metade do Ceará, revelando ainda os saldos migratórios da "batalha da borracha" e até mesmo anteriores a esta fase. Para o Amazonas, pouco mais de $40 \%$ veio da própria região, principalmente do Acre $^{72}$ e Pará; e para o Pará, pouco mais de dez por cento.

O caso do Pará deve ser mencionado em separado: quase 3/4 dos imigrantes de fora do Estado vieram do nordeste e de Goiás. Merece destaque, além do contingente vindo desse último Estado (mais de 30 mil), aquele provindo do Maranhão (mais de 36 mil). Esses fluxos migratórios indicam o avanço da frente pioneira rural vinda do nordeste e de Goiás (compare-se a parte dos fluxos, na coluna "fora da Região", que se dirigem para Belém com os do Estado).

${ }^{72} \mathrm{O}$ que ajuda a compreender os movimentos migratórios desse Estado tratados em páginas anteriores. 
VI b - Estado de proveniência dos migrantes de fora do

Estado Unidades da Federação, Região norte, 1970 (continuação)

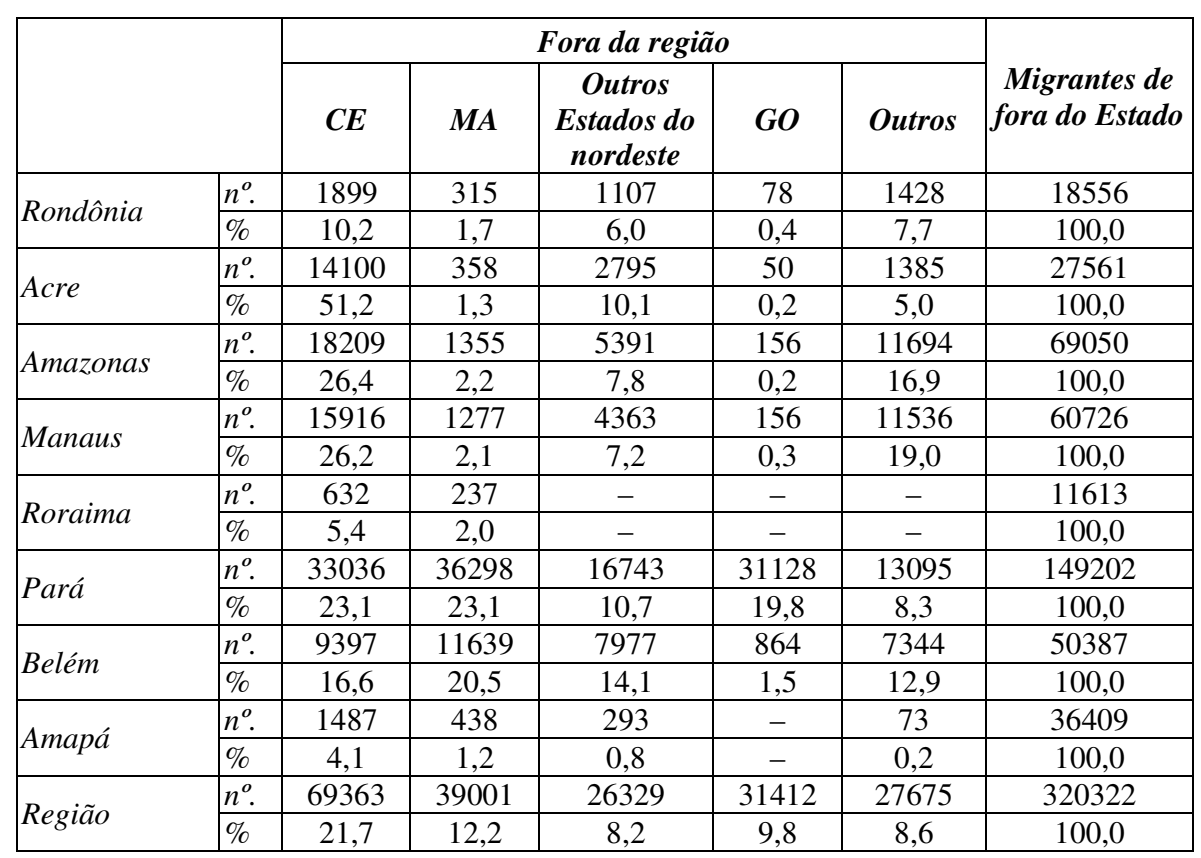

Fonte: Tabulações especiais do Censo Demográfico, 1970

* Incluídos os migrantes sem especificação de proveniências (pressuposto de que seja de fora da unidade da Federação).

Os dados da Tabela VI mostram também os diferenciais das correntes migratórias que se dirigem para as duas principais cidades da região, entre si e em relação com os que vão para o interior. Mais explicitamente, comparando-se as correntes migratórias para Manaus (116.472 no total) com as para o interior do Estado (62.317 no total), nota-se que, para este último lugar, há muito maior proporção que é oriunda do Amazonas mesmo. De fato, enquanto apenas $13 \%$ vieram de fora do Estado para o interior dele, mais da metade dos que se dirigem para a Capital veio de outras áreas da Amazônia e de fora dela. De outro ângulo, apenas pouco mais de 8 mil, de quase 70 mil dos imigrantes para o Amazonas, que vieram de fora do Estado, localizou-se no interior.
O que se pode depreender destes dados, em conjunto, quanto aos fluxos rurais-urbanos, é que os que se dirigem às cidades do interior do Amazonas provêm, na sua quase totalidade, das zonas rurais do próprio Estado e aqueles que daí se dirigem para Manaus juntam-se a segmento importante (1/5 a 1/4 do total de imigrantes para esta cidade) proveniente de zonas rurais de outros Estados; nesta cidade, como nas outras da região, as correntes migratórias principais são urbano-urbanas.

Para o Estado do Pará, as correntes migratórias diferenciam-se bastante. Sobressai a alta porcentagem dos imigrantes do interior que provêm de fora da Região. Para um total de 130 mil imigrantes de fora que se dirigiram para o Pará, mais de $70 \%$ localizaram-se no interior. A Tabela VI, referente à unidade da Federação de procedência, indica, como vimos, que se trata de maranhenses, goianos e cearenses que se juntam a outros nordestinos num total de mais de 87 mil pessoas. Infelizmente os dados de que dispomos não nos permitem distinguir as ondas mais antigas (presumivelmente cearenses) da mais recente (maranhenses e goianos) que penetram no leste do Pará como extensão gradativa da frente pioneira.

Os movimentos migratórios aqui examinados, com ênfase na magnitude dos fluxos, expressam, no fundo, a redistribuição da massa de trabalho demandada segundo os interesses econômicos e políticos em jogo governos federal e estaduais, empresas industriais e de serviços, empresas agropecuárias e mineradoras, autônomas urbanas e rurais, latifúndio extrativo e pecuário e sítios - na organização regional e nacional. Convém desenvolver esta hipótese, inicialmente no âmbito rural e depois no meio urbano. 